Kragujevac Journal of Mathematics

Volume 45(5) (2021), Pages 761-780.

\title{
SOLVABILITY FOR MULTI-POINT BVP OF NONLINEAR FRACTIONAL DIFFERENTIAL EQUATIONS AT RESONANCE WITH THREE DIMENSIONAL KERNELS
}

\author{
ZIDANE BAITICHE ${ }^{1}$, MAAMAR BENBACHIR ${ }^{2}$, AND KADDOUR GUERBATI ${ }^{1}$ \\ ABstract. This work deals with the BVP multi-point existence of solutions of a \\ nonlinear fractional differential equations at resonance, where the kernel's dimension \\ of the fractional differential operator is equal to three. Our results are based on \\ Mawhin's theory of coincidence. As application, we give an example to illustrate \\ our results.
}

\section{INTRODUCTION}

The present work concerns a kind of fractional differential equation which can be written as $L x=N x$, where $\mathrm{L}$ is a linear Fredholm operator of index zero, and $N$ is a nonlinear operator. It is well known that if the kernel of the linear part contains only zero, the corresponding boundary value problem is called non-resonant. In this case, $\mathrm{L}$ is invertible, the equation can be reduced to a fixed point problem for the $L^{-1} N$ operator. Otherwise, if $L$ is a non-invertible, i.e., $\operatorname{dim} \operatorname{ker} L \geq 1$, then the problem is said to be at resonance, and then the problem can be solved by using the coincidence degree theory. The higher value of $\operatorname{dim} k e r L$ is the more difficult. Recently, many authors investigated the existence of solutions for fractional differential equations at resonance. For instance, see $[3-6,9-11,15,16,18,19,32]$ and the references therein.

The case of $\operatorname{dim} \operatorname{ker} L=1$ has been discussed by many authors $[3,4,6,9-11,16,18$, 19,32]. In [6], Z. Bai and Y. Zhang investigated the boundary value problem for a

Key words and phrases. Fractional differential equations, fractional Caputo derivative, multi-point boundary value problem, resonance, three dimensional kernels, coincidence degree theory.

2010 Mathematics Subject Classification. Primary: 34A08; Secondary: 34B15, 34B25.

DOI 10.46793/KgJMat2105.761B

Received: November 17, 2018.

Accepted: May 20, 2019. 
fractional differential equation with nonlinear growth with $\operatorname{dim} \operatorname{ker} L=1$

$$
\left\{\begin{array}{l}
D_{0^{+}}^{\alpha} u(t)=f\left(t, u(t), D_{0^{+}}^{\alpha-1} u(t)\right), \quad t \in[0,1] \\
u(0)=0, \quad u(1)=\sigma u(\eta)
\end{array}\right.
$$

where $D_{0^{+}}^{\alpha}$ is the standard Riemann-Liouville derivative, $1<\alpha \leq 2, f:[0,1] \times \mathbb{R}^{2} \rightarrow \mathbb{R}$ is continuous and $\sigma \in(0, \infty), \eta \in(0,1)$ are given constants such that $\sigma \eta^{\alpha-1}=1$.

Z. $\mathrm{Hu}$ et al. in [10] prove the existence of solutions of two-point boundary value problem for a fractional differential equation at resonance with $\operatorname{dim} \operatorname{ker} L=1$

$$
\left\{\begin{array}{l}
D_{0^{+}}^{\alpha} u(t)=f\left(t, u(t), u^{\prime}(t)\right), \quad t \in[0,1] \\
u(0)=0, \quad u(1)=u^{\prime}(1)
\end{array}\right.
$$

where $D_{0^{+}}^{\alpha}$ is the Caputo fractional derivative, $1<\alpha \leq 2, f:[0,1] \times \mathbb{R}^{2} \rightarrow \mathbb{R}$ satisfies the Caratheodory conditions.

$\mathrm{L}$. $\mathrm{Hu}$ et al. studied in [11] a two-point boundary value problem for fractional differential equation at resonance with $\operatorname{dim} \operatorname{ker} L=1$ :

$$
\left\{\begin{array}{l}
D_{0^{+}}^{\alpha} u(t)=f\left(t, u(t), D_{0^{+}}^{\alpha-1} u(t), D_{0^{+}}^{\alpha-2} u(t), \ldots, D_{0^{+}}^{\alpha-(N-1)} u(t)\right), \\
u(0)=D_{0^{+}}^{\alpha-2} u(0)=\cdots=D_{0^{+}}^{\alpha-(N-1)} u(0)=0, \quad D_{0^{+}}^{\alpha-1} u(0)=D_{0^{+}}^{\alpha-1} u(1),
\end{array}\right.
$$

where $0<t<1, N-1<\alpha \leq N, D_{0^{+}}^{\alpha}$ is Riemann-Liouville fractional derivative, and $f:[0,1] \times \mathbb{R}^{2} \rightarrow \mathbb{R}$ is a continuous function.

For the case $\operatorname{dim} \operatorname{ker} L=2$, Bai and Zhang established in [5] the existence of at least one solution for the m-point boundary value problem for fractional differential equation at resonance with $\operatorname{dim} \operatorname{ker} L=2$

$$
\left\{\begin{array}{l}
D_{0^{+}}^{\alpha} u(t)=f\left(t, u(t), D_{0^{+}}^{\alpha-2} u(t), D_{0^{+}}^{\alpha-1} u(t)\right), \quad t \in(0,1) \\
I_{0^{+}}^{\alpha-1} u(0)=0, \quad D_{0^{+}}^{\alpha-1} u(0)=D_{0^{+}}^{3-\alpha}(\eta), \quad u(1)=\sum_{i=1}^{m} \alpha_{i} u\left(\eta_{i}\right)
\end{array}\right.
$$

where $2<\alpha<3,0<\eta \leq 1,0<\eta_{1}<\eta_{2}<\cdots<\eta_{m}<1, m \geq 2, \sum_{i=1}^{m} \alpha_{i} \eta_{i}^{\alpha-1}=$ $\sum_{i=1}^{m} \alpha_{i} \eta_{i}^{\alpha-2}=1 . D_{0^{+}}^{\alpha}$ and $\bar{I}_{0^{+}}^{\alpha}$ are the standard Riemann-Liouville fractional derivative and fractional integral respectively and $f:[0,1] \times \mathbb{R}^{3} \rightarrow \mathbb{R}$ satisfies the Caratheodory conditions. The results are obtained under the assumption that:

$$
R=\frac{1}{\alpha} \eta^{\alpha} \frac{\Gamma(\alpha) \Gamma(\alpha-1)}{\Gamma(2 \alpha-1)}\left[1-\sum_{i=1}^{m} \alpha_{i} \eta_{i}^{2 \alpha-2}\right]-\frac{1}{\alpha-1} \eta^{\alpha-1} \frac{(\Gamma(\alpha))^{2}}{\Gamma(2 \alpha)}\left[1-\sum_{i=1}^{m} \alpha_{i} \eta_{i}^{2 \alpha-1}\right] \neq 0
$$

W. Jiang showed in [15] an existence result for the boundary value problem of fractional differential equation at resonance with $\operatorname{dim} \operatorname{ker} L=2$ :

$$
\left\{\begin{array}{l}
D_{0^{+}}^{\alpha} u(t)=f\left(t, u(t), D_{0^{+}}^{\alpha-1} u(t)\right), \quad t \in J=[0,1], \\
u(0)=0, \quad D_{0^{+}}^{\alpha-1} u(0)=\sum_{i=1}^{m} a_{i} D_{0^{+}}^{\alpha-1}\left(\xi_{i}\right), \quad D_{0^{+}}^{\alpha-2} u(0)=\sum_{j=1}^{n} b_{j} D_{0^{+}}^{\alpha-2}\left(\eta_{j}\right),
\end{array}\right.
$$

where $2<\alpha<3, D_{0^{+}}^{\alpha}$ is Riemann-Liouville fractional derivative, $0<\xi_{1}<\xi_{2}<$ $\cdots<\xi_{m}<1,0<\eta_{1}<\eta_{2}<\cdots<\eta_{n}<1, \sum_{i=1}^{m} a_{i}=1, \sum_{j=1}^{n} b_{j}=1, \sum_{j=1}^{n} b_{j} \eta_{j}=1$, 
$f:[0,1] \times \mathbb{R}^{2} \rightarrow \mathbb{R}$ satisfies the Caratheodory conditions. The results are obtained under the assumption that

$$
\frac{1}{3}\left(1-\sum_{j=1}^{n} b_{j} \eta_{j}^{3}\right) \sum_{i=1}^{m} a_{i} \xi_{i}-\frac{1}{2}\left(1-\sum_{j=1}^{n} b_{j} \eta_{j}^{2}\right) \sum_{i=1}^{m} a_{i} \xi_{i}^{2} \neq 0 .
$$

Motivated by the results cited above, we investigate the solvability of multi-point boundary value problem of nonlinear fractional differential equation at resonance with $\operatorname{dim} \operatorname{ker} L=3$

$$
\left\{\begin{array}{l}
\left(\phi(t){ }^{C} D_{0^{+}}^{\alpha} u(t)\right)^{\prime}=f\left(t, u(t), u^{\prime}(t), u^{\prime \prime}(t), u^{\prime \prime \prime}(t),{ }^{C} D_{0^{+}}^{\alpha} u(t)\right), \quad t \in I, \\
u(0)=0, \quad{ }^{C} D_{0^{+}}^{\alpha} u(0)=0, \quad u^{\prime \prime \prime}(0)=\sum_{i=1}^{m} a_{i} u^{\prime \prime \prime}\left(\xi_{i}\right), \\
u^{\prime \prime}(0)=\sum_{j=1}^{l} b_{j} u^{\prime \prime}\left(\eta_{j}\right), \quad u^{\prime}(1)=\sum_{k=1}^{n} c_{k} u^{\prime}\left(\rho_{k}\right)
\end{array}\right.
$$

where ${ }^{C} D_{0^{+}}^{\alpha}$ is the Caputo fractional derivative, $3<\alpha \leq 4,0<\xi_{1}<\cdots<\xi_{m}<$ $1,0<\eta_{1}<\cdots<\eta_{l}<1,0<\rho_{1}<\cdots<\rho_{n}<1, a_{i}, b_{j}, c_{k} \in \mathbb{R}, i=1, \ldots, m, j=$ $1, \ldots, l, k=1, \ldots, n, I=[0,1], \phi(t) \in C^{1}([0,1]), \mu=\min _{t \in I} \phi(t)>0$ and $f:[0,1] \times$ $\mathbb{R}^{5} \rightarrow \mathbb{R}$ is a Caratheodory function, that is,

(i) for each $x \in \mathbb{R}^{5}$, the function $x \rightarrow f(t, x)$ is Lebesgue measurable;

(ii) for almost every $t \in[0,1]$, the function $t \rightarrow f(t, x)$ is continuous on $\mathbb{R}^{5}$;

(iii) for each $r>0$, there exists $\varphi_{r}(t) \in L^{1}([0,1], \mathbb{R})$ such that, for a.e. $t \in[0,1]$ and every $|x| \leq r$, we have $|f(t, x)| \leq \varphi_{r}(t)$.

In this work, we will always suppose that the following conditions hold.

$\left(H_{1}\right) \sum_{i=1}^{m} a_{i}=\sum_{j=1}^{l} b_{j}=\sum_{k=1}^{n} c_{k}=1, \sum_{j=1}^{l} b_{j} \eta_{j}=0, \sum_{k=1}^{n} c_{k} \rho_{k}=\sum_{k=1}^{n} c_{k} \rho_{k}^{2}=1$. $\left(\mathrm{H}_{2}\right)$

$$
\Delta=\left|\begin{array}{lll}
d_{11} & d_{12} & d_{13} \\
d_{21} & d_{22} & d_{23} \\
d_{31} & d_{32} & d_{33}
\end{array}\right| \neq 0
$$

where for $\nu=1,2,3$, we define

$$
\begin{aligned}
& d_{\nu 1}=\sum_{i=1}^{m} a_{i} \int_{0}^{\xi_{i}} \frac{s^{\nu}\left(\xi_{i}-s\right)^{\alpha-4}}{\nu \phi(s)} d s, \quad d_{\nu 2}=\sum_{j=1}^{l} b_{j} \int_{0}^{\eta_{j}} \frac{s^{\nu}\left(\eta_{j}-s\right)^{\alpha-3}}{\nu \phi(s)} d s \\
& d_{\nu 3}=\int_{0}^{1} \frac{s^{\nu}(1-s)^{\alpha-2}}{\nu \phi(s)} d s-\sum_{k=1}^{n} c_{k} \int_{0}^{\rho_{k}} \frac{s^{\nu}\left(\rho_{k}-s\right)^{\alpha-2}}{\nu \phi(s)} d s .
\end{aligned}
$$

The rest of this work is organized as follows. In Section 2, we introduce some notations, definitions and lemmas which will be used later. In Section 3, we present and prove our main results by applying the coincidence degree continuation theorem. Finally, in Section 4 we provide an example. 


\section{Preliminaries}

In this section, we present the necessary definitions and lemmas from fractional calculus theory. These definitions and properties can be found in recent literature, see for example $[17,26-28,30]$.

Definition 2.1. Let $\alpha>0$, and $u$ a function $u:(0, \infty) \rightarrow \mathbb{R}$. The Riemann-Liouville fractional integral of order $\alpha$ of $u$ is defined by

$$
I_{0^{+}}^{\alpha} u(t)=\frac{1}{\Gamma(\alpha)} \int_{0}^{t}(t-s)^{\alpha-1} u(s) d s,
$$

provided that the right-hand side is pointwise defined on $(0, \infty)$.

Remark 2.1. The notation $\left.I_{0^{+}}^{\alpha} u(t)\right|_{t=0}$ means that the limit is taken at almost all points of the right-sided neighborhood $(0, \varepsilon), \varepsilon>0$, of 0 as follows:

$$
\left.I_{0^{+}}^{\alpha} u(t)\right|_{t=0}=\lim _{t \rightarrow 0+} I_{0^{+}}^{\alpha} u(t) .
$$

Generally $\left[\left.I_{0^{+}}^{\alpha} u(t)\right|_{t=0}\right]$ is not necessarily zero. For instance, let $\alpha \in(0,1), u(t)=t^{-\alpha}$. Then

$$
\left.I_{0^{+}}^{\alpha} t^{-\alpha}\right|_{t=0}=\lim _{t \rightarrow 0+} \frac{1}{\Gamma(\alpha)} \int_{0}^{t}(t-s)^{\alpha-1} s^{-\alpha} d s=\lim _{t \rightarrow 0+} \Gamma(1-\alpha)=\Gamma(1-\alpha) .
$$

Definition 2.2. Let $\alpha>0$. The Caputo fractional derivative of order $\alpha$ of a function $u:(0, \infty) \rightarrow \mathbb{R}$ is given by

$$
{ }^{C} D_{0^{+}}^{\alpha} u(t)=I_{0^{+}}^{n-\alpha} u^{(n)}(t)=\frac{1}{\Gamma(n-\alpha)} \int_{0}^{t}(t-s)^{n-\alpha-1} u^{(n)}(s) d s,
$$

where $n=[\alpha]+1,[\alpha]$ denotes the integer part of real number $\alpha$, provided that the right-hand side is pointwise defined on $(0, \infty)$.

Lemma 2.1. Let $\alpha, \eta>0, n=[\alpha]+1$, then the following relations hold

$$
{ }^{C} D_{0^{+}}^{\alpha} t^{\eta}=\frac{\Gamma(\eta+1)}{\Gamma(\eta-\alpha+1)} t^{\eta-\alpha}, \quad \eta>n-1,
$$

and

$$
{ }^{C} D_{0^{+}}^{\alpha} t^{k}=0, \quad k=0, \ldots, n-1 .
$$

Lemma 2.2. Let $\alpha, \beta \geq 0$ and $u \in L^{1}([0,1])$. Then $I_{0^{+}}^{\alpha} I_{0^{+}}^{\beta} u(t)=I_{0^{+}}^{\alpha+\beta} u(t)$ and ${ }^{C} D_{0^{+}}^{\alpha} I_{0^{+}}^{\alpha} u(t)=u(t)$ for all $t \in[0,1]$

Lemma 2.3. Let $\alpha>0, n=[\alpha]+1$. Then

$$
I_{0^{+}}^{\alpha}\left({ }^{C} D_{0^{+}}^{\alpha} u(t)\right)=u(t)+\sum_{k=0}^{n-1} \delta_{k} t^{k}, \quad \delta_{k} \in \mathbb{R} .
$$

Lemma 2.4. Let $\alpha>0$ and $n=[\alpha]+1$. If ${ }^{C} D_{0^{+}}^{\alpha} u(t) \in C[0,1]$, then $u(t) \in$ $C^{n-1}([0,1])$. 
Proof. Let $h(t) \in C[0,1]$, such that ${ }^{C} D_{0^{+}}^{\alpha} u(t)=h(t)$, then, from Lemma 2.2, we have

$$
u(t)=I_{0^{+}}^{\alpha} h(t)+\sum_{k=0}^{n-1} \delta_{k} t^{k}, \quad \delta_{k} \in \mathbb{R} .
$$

It is easy to check that $u(t) \in C^{n-1}([0,1])$.

Lemma 2.5. Let $\alpha>0, u \in L^{1}([0,1], \mathbb{R})$. Then, for all $t \in[0,1]$, we have

$$
I_{0^{+}}^{\alpha+1} u(t) \leq\left\|I_{0^{+}}^{\alpha} u\right\|_{L^{1}} .
$$

Proof. Let $u \in L^{1}([0,1], \mathbb{R})$, from Lemma 2.2 , we have

$$
I_{0^{+}}^{\alpha+1} u(t)=I_{0^{+}}^{1} I_{0^{+}}^{\alpha} u(t)=\int_{0}^{t} I_{0^{+}}^{\alpha} u(s) d s \leq \int_{0}^{1}\left|I_{0^{+}}^{\alpha} u(s)\right| d s=\left\|I_{0^{+}}^{\alpha} u\right\|_{L^{1}} .
$$

Lemma 2.6 ([30]). The fractional integral $I_{0^{+}}^{\alpha}, \alpha>0$, is bounded in $L^{1}([0,1], \mathbb{R})$ with

$$
\left\|I_{0^{+}}^{\alpha} u\right\|_{L^{1}} \leq \frac{\|u\|_{L^{1}}}{\Gamma(\alpha+1)}
$$

Now, let us recall some notations about the coincidence degree continuation theorem. For more details see [25].

Definition 2.3. Let $X$ and $Y$ be real Banach spaces. A linear operator $L$ : $\operatorname{dom} L \subset$ $X \rightarrow Y$ is said to be a Fredholm operator of index zero if

(1) $\operatorname{Im} L$ is a closed subset of $Y$;

(2) $\operatorname{dim} \operatorname{ker} L=\operatorname{codim} \operatorname{Im} L<\infty$.

It follows from Definition 2.3 that there exist continuous projectors $P: X \rightarrow X$ and $Q: Y \rightarrow Y$ such that

$\operatorname{ker} L=\operatorname{Im} P, \quad \operatorname{Im} L=\operatorname{ker} Q, \quad X=\operatorname{ker} L \oplus \operatorname{ker} P, \quad Y=\operatorname{Im} L \oplus \operatorname{Im} Q$.

It follows that

$$
L_{p}=\left.L\right|_{\operatorname{dom} L \cap \operatorname{ker} P: \operatorname{dom} L \cap \operatorname{ker} P \rightarrow \operatorname{Im} L}
$$

is invertible. We denote the inverse of this map by $K_{p}$.

Definition 2.4. Let $L$ be a Fredholm operator of index zero. If $\Omega$ is an open bounded subset of $X$ and $\operatorname{dom} L \cap \Omega \neq \emptyset$. The map $N: \bar{\Omega} \rightarrow X$ will be called $L$-compact on $\bar{\Omega}$ if

(1) $Q N(\bar{\Omega})$ is bounded;

(2) $K_{P, Q} N=K_{p}(I-Q) N: \bar{\Omega} \rightarrow X$ is compact.

Theorem 2.1. Let $L: \operatorname{dom} L \subset X \rightarrow Y$ be a Fredholm operator of index zero and $N: X \rightarrow Y$ L-compact on $\bar{\Omega}$. Assume that the following conditions are satisfied:

(1) $L x \neq \lambda N x$ for every $(x, \lambda) \in[(\operatorname{dom} L \backslash \operatorname{ker} L) \cap \partial \Omega] \times(0,1)$;

(2) $N x \notin \operatorname{Im} L$ for every $x \in \operatorname{ker} L \cap \partial \Omega$;

(3) $\operatorname{deg}\left(\left.Q N\right|_{\operatorname{ker} L}, \Omega \cap \operatorname{ker} L, 0\right) \neq 0$, where $Q: Y \rightarrow Y$ is a projection such that $\operatorname{Im} L=\operatorname{ker} Q$. 
Then, the abstract equation $L x=N x$ has at least one solution in $\operatorname{dom} L \cap \bar{\Omega}$.

For our purpose and according to Lemma 2.4, the adequate functional space is:

$$
X=\left\{u:{ }^{C} D_{0^{+}}^{\alpha} u \in C([0,1], \mathbb{R}), u \text { satisfies boundary value conditions of }(1.1)\right\}
$$

endowed with the norm:

$$
\|u\|_{X}=\sum_{i=0}^{3}\left\|u^{(i)}\right\|_{\infty}+\left\|{ }^{C} D_{0^{+}}^{\alpha} u\right\|_{\infty}, \quad \text { where }\|u\|_{\infty}=\max _{t \in[0,1]}|u(t)| .
$$

By means of the functional analysis theory, we can prove that $\left(X,\|\cdot\|_{X}\right)$ is a Banach space.

Let $Y=L^{1}[0,1]$ be the Lebesgue space of real measurable functions $t \mapsto y(t)$ defined on $[0,1]$ and such that $t \mapsto|y(t)|$ is Lebesgue integrable. $\mathrm{Y}$ is a Banach space with the norm $\|y\|_{L^{1}}=\int_{0}^{1}|y(t)| d t$. Define $L$ to be the linear operator from dom $L \cap X$ to $Y$

$$
L u=\left(\phi^{C} D_{0^{+}}^{\alpha} u\right)^{\prime}, \quad u \in \operatorname{dom} L,
$$

where

$$
\operatorname{dom} L=\left\{u \in X:{ }^{C} D_{0^{+}}^{\alpha} u(t) \text { is absolutely continuous on }[0,1]\right\}
$$

and define the operator $N: X \rightarrow Y$ as:

$$
N u(t)=f\left(t, u(t), u^{\prime}(t), u^{\prime \prime}(t), u^{\prime \prime \prime}(t),{ }^{C} D_{0^{+}}^{\alpha} u(t)\right), \quad t \in[0,1] .
$$

Then the boundary value problem (1.1) can be written in abstract form as:

$$
L u=N u, \quad u \in \operatorname{dom} L .
$$

To study the compactness of operator $N$, we need the following lemma.

Lemma 2.7. $U \subset X$ is a relatively compact set in $X$ if and only if $U$ is uniformly bounded and equicontinuous. Here uniformly bounded means there exists $M>0$ such that for every $u \in U$

$$
\|u\|_{X}=\sum_{i=0}^{3}\left\|u^{(i)}\right\|_{\infty}+\left\|{ }^{C} D_{0^{+}}^{\alpha} u\right\|_{\infty} \leq M
$$

and equicontinuous means that for all $\varepsilon>0$, exists $\delta>0$, such that

$$
\left|u^{(i)}\left(t_{1}\right)-u^{(i)}\left(t_{2}\right)\right|<\varepsilon, \quad \text { for all } u \in U, t_{1}, t_{2} \in I,\left|t_{1}-t_{2}\right|<\delta, i \in\{0,1,2,3\},
$$

and

$$
\left|{ }^{C} D_{0^{+}}^{\alpha} u\left(t_{1}\right)-{ }^{C} D_{0^{+}}^{\alpha} u\left(t_{2}\right)\right|<\varepsilon, \quad \text { for all } u \in U, t_{1}, t_{2} \in I,\left|t_{1}-t_{2}\right|<\delta .
$$




\section{MAin Results}

In this section we shall present and prove our main result.

Lemma 3.1. Let $y \in Y, \phi \in C^{1}[0,1], \min _{t \in I} \phi(t)>\mu>0$, and suppose that $\left(H_{1}\right)$ holds. Then $u \in X$ is the solution of the following fractional differential equation:

$$
\left\{\begin{array}{l}
\left(\phi(t){ }^{C} D_{0^{+}}^{\alpha} u(t)\right)^{\prime}=y(t), \quad t \in I=[0,1], \\
u(0)=0, \quad{ }^{C} D_{0^{+}}^{\alpha} u(0)=0, \quad u^{\prime \prime \prime}(0)=\sum_{i=1}^{m} a_{i} u^{\prime \prime \prime}\left(\xi_{i}\right), \\
u^{\prime \prime}(0)=\sum_{j=1}^{l} b_{j} u^{\prime \prime}\left(\eta_{j}\right), u^{\prime}(1)=\sum_{k=1}^{n} c_{k} u^{\prime}\left(\rho_{k}\right),
\end{array}\right.
$$

where $u$ is given by

$$
u(t)=\sum_{i=1}^{3} \delta_{i} t^{i}+\frac{1}{\Gamma(\alpha)} \int_{0}^{t} \frac{(t-s)^{\alpha-1}}{\phi(s)} \int_{0}^{s} y(r) d r d s, \quad \delta_{1}, \delta_{2}, \delta_{3} \in \mathbb{R}
$$

and

$$
T_{1}(y)=T_{2}(y)=T_{3}(y)=0,
$$

where $T_{1}, T_{2}, T_{3}: Y \rightarrow Y$ are three linear operators defined as follow:

$$
\begin{aligned}
& T_{1}(y)=\sum_{i=1}^{m} a_{i} \int_{0}^{\xi_{i}} \frac{\left(\xi_{i}-s\right)^{\alpha-4}}{\phi(s)} \int_{0}^{s} y(r) d r d s, \\
& T_{2}(y)=\sum_{j=1}^{l} b_{j} \int_{0}^{\eta_{j}} \frac{\left(\eta_{j}-s\right)^{\alpha-3}}{\phi(s)} \int_{0}^{s} y(r) d r d s, \\
& T_{3}(y)=\int_{0}^{1} \frac{(1-s)^{\alpha-2}}{\phi(s)} \int_{0}^{s} y(r) d r d s-\sum_{k=1}^{n} c_{k} \int_{0}^{\rho_{k}} \frac{\left(\rho_{k}-s\right)^{\alpha-2}}{\phi(s)} \int_{0}^{s} y(r) d r d s .
\end{aligned}
$$

Proof. Let $u$ be a solution of problem (3.1). Then we have

$$
\phi(t)^{C} D_{0^{+}}^{\alpha} u(t)=\delta+\int_{0}^{t} y(s) d s, \quad \delta \in \mathbb{R} .
$$

The hypothesis ${ }^{C} D_{0^{+}}^{\alpha} u(0)=0$ and $\min _{t \in I} \phi(t)>0$, allow us to write

$$
{ }^{C} D_{0^{+}}^{\alpha} u(t)=\frac{1}{\phi(t)} \int_{0}^{t} y(s) d s .
$$

By Lemma 2.3, we get that

$$
u(t)=\sum_{i=0}^{3} \delta_{i} t^{i}+\frac{1}{\Gamma(\alpha)} \int_{0}^{t} \frac{(t-s)^{\alpha-1}}{\phi(s)} \int_{0}^{s} y(r) d r d s, \quad \delta_{0}, \delta_{1}, \delta_{2}, \delta_{3} \in \mathbb{R} .
$$

$u(0)=0$, implies that

$$
u(t)=\sum_{i=1}^{3} \delta_{i} t^{i}+\frac{1}{\Gamma(\alpha)} \int_{0}^{t} \frac{(t-s)^{\alpha-1}}{\phi(s)} \int_{0}^{s} y(r) d r d s, \quad \delta_{1}, \delta_{2}, \delta_{3} \in \mathbb{R} .
$$


By $u^{\prime \prime \prime}(0)=\sum_{i=1}^{m} a_{i} u^{\prime \prime \prime}\left(\xi_{i}\right)$ and $\sum_{i=1}^{l} a_{i}=1$, we obtain

$$
\sum_{i=1}^{l} a_{i} \int_{0}^{\xi_{i}} \frac{\left(\xi_{i}-s\right)^{\alpha-4}}{\phi(s)} \int_{0}^{s} y(r) d r d s=0
$$

From the conditions $u^{\prime \prime}(0)=\sum_{j=1}^{l} b_{j} u^{\prime \prime}\left(\eta_{j}\right)$ and $\sum_{j=1}^{l} b_{j}=1, \sum_{j=1}^{l} b_{j} \eta_{j}=0$, we get

$$
\sum_{j=1}^{l} b_{j} \int_{0}^{\eta_{j}} \frac{\left(\eta_{j}-s\right)^{\alpha-3}}{\phi(s)} \int_{0}^{s} y(r) d r d s=0 .
$$

Combining $u^{\prime}(1)=\sum_{k=1}^{n} c_{k} u^{\prime}\left(\rho_{k}\right), \sum_{k=1}^{n} c_{k}=1$ and $\sum_{k=1}^{n} c_{k} \rho_{k}=1, \sum_{k=1}^{n} c_{k} \rho_{k}^{2}=1$, we find

$$
\int_{0}^{1} \frac{(1-s)^{\alpha-2}}{\phi(s)} \int_{0}^{s} y(r) d r d s-\sum_{k=1}^{n} c_{k} \int_{0}^{\rho_{k}} \frac{\left(\rho_{k}-s\right)^{\alpha-2}}{\phi(s)} \int_{0}^{s} y(r) d r d s=0
$$

Thus,

$$
T_{1}(y)=T_{2}(y)=T_{3}(y)=0
$$

On the other hand, we let

$$
u(t)=\sum_{i=1}^{3} \delta_{i} t^{i}+\frac{1}{\Gamma(\alpha)} \int_{0}^{t} \frac{(t-s)^{\alpha-1}}{\phi(s)} \int_{0}^{s} y(r) d r d s
$$

where $\delta_{1}, \delta_{2}, \delta_{3}$ are arbitrary constants. It is clear that $u(0)=0$, in view of Lemmas 2.1 and 2.2 , we obtain

$$
{ }^{C} D_{0^{+}}^{\alpha} u(t)=\frac{1}{\phi(t)} \int_{0}^{t} y(s) d s .
$$

Thus, ${ }^{C} D_{0^{+}}^{\alpha} u(0)=0$ and $\left(\phi(t)^{C} D_{0^{+}}^{\alpha} u(t)\right)^{\prime}=y(t)$ for all $t \in[0,1]$.

If (3.3) holds, we can calculate the following equations

$$
\begin{gathered}
u^{\prime \prime \prime}(0)-\sum_{i=1}^{m} a_{i} u^{\prime \prime \prime}\left(\xi_{i}\right)=\frac{T_{1}(y)}{\Gamma(\alpha-3)}=0, \quad u^{\prime \prime}(0)-\sum_{j=1}^{l} b_{j} u^{\prime \prime}\left(\eta_{j}\right)=\frac{T_{2}(y)}{\Gamma(\alpha-2)}=0, \\
u^{\prime}(1)-\sum_{k=1}^{n} c_{k} u^{\prime}\left(\rho_{k}\right)=\frac{T_{3}(y)}{\Gamma(\alpha-1)}=0,
\end{gathered}
$$

so, $u$ is the solution of the problem (3.1), this completes the proof.

Lemma 3.2. Assume that $\left(H_{1}\right)$ and $\left(H_{2}\right)$ hold. Let $\phi \in C^{1}([0,1]), \min _{t \in[0,1]} \phi(t)>$ $\mu>0$, then $L: \operatorname{dom} L \subset X \rightarrow Y$ is a Fredholm operator of index zero, and the inverse linear operator $K_{p}=L_{p}^{-1}: \operatorname{Im} L \rightarrow \operatorname{dom} L \cap \operatorname{ker} P$ is defined by

$$
\left(K_{p} y\right)(t)=\frac{1}{\Gamma(\alpha)} \int_{0}^{t} \frac{(t-s)^{\alpha-1}}{\phi(s)} \int_{0}^{s} y(r) d r d s .
$$

It satisfies

$$
\left\|K_{p} y\right\|_{X} \leq \frac{4+\Gamma(\alpha-2)}{\mu \Gamma(\alpha-2)}\|y\|_{L^{1}}
$$


Proof. It is clear that ker $L=\left\{u: u(t)=\sum_{k=1}^{3} \delta_{k} t^{k}, \delta_{1}, \delta_{2}, \delta_{3} \in \mathbb{R}\right\}$. Furthermore, Lemma 3.1 implies

$$
\operatorname{Im} L=\left\{y \in Y: T_{1}(y)=T_{2}(y)=T_{3}(y)=0\right\} .
$$

Consider continuous linear mapping $Q: Y \rightarrow Y$ defined by

$$
Q y=Q_{1}(y)+Q_{2}(y) t+Q_{3}(y) t^{2}
$$

where $Q_{1}, Q_{2}, Q_{3}: Y \rightarrow Y$ are three linear operators defined as follows

$$
\begin{aligned}
& Q_{1}(y)=\frac{1}{\Delta}\left(e_{11} T_{1}(y)+e_{12} T_{2}(y)+e_{13} T_{3}(y)\right), \\
& Q_{2}(y)=\frac{1}{\Delta}\left(e_{21} T_{1}(y)+e_{22} T_{2}(y)+e_{23} T_{3}(y)\right), \\
& Q_{3}(y)=\frac{1}{\Delta}\left(e_{31} T_{1}(y)+e_{32} T_{2}(y)+e_{33} T_{3}(y)\right),
\end{aligned}
$$

$e_{i j}, i, j=1,2,3$, are the algebraic complements of $d_{i j}$.

We will prove that $\operatorname{ker} Q=\operatorname{Im} L$. Obviously, $\operatorname{Im} L \subset \operatorname{ker} Q$. As well, if $y \in \operatorname{ker} Q$, then

$$
\left\{\begin{array}{l}
e_{11} T_{1}(y)+e_{12} T_{2}(y)+e_{13} T_{3}(y)=0 \\
e_{21} T_{1}(y)+e_{22} T_{2}(y)+e_{23} T_{3}(y)=0 \\
e_{31} T_{1}(y)+e_{32} T_{2}(y)+e_{33} T_{3}(y)=0
\end{array}\right.
$$

The determinant of coefficients for (3.8) is $\Delta^{2} \neq 0$. We find $T_{1}(y)=T_{2}(y)=T_{3}(y)=0$ and that implies $y \in \operatorname{Im} L$. So, $\operatorname{ker} Q \subset \operatorname{Im} L$. Now, we prove $Q^{2} y=Q y, y \in Y$. For $y \in Y$, we have

$$
\begin{aligned}
Q_{1}^{2}(y) & =\frac{1}{\Delta}\left[e_{11} T_{1}\left(Q_{1}(y)\right)+e_{12} T_{2}\left(Q_{1}(y)\right)+e_{13} T_{3}\left(Q_{1}(y)\right)\right] \\
& =\frac{1}{\Delta}\left(e_{11} d_{11}+e_{12} d_{21}+e_{13} d_{31}\right) Q_{1} y \\
& =Q_{1} y \\
Q_{1}\left(Q_{2}(y) t\right) & =\frac{1}{\Delta}\left[e_{11} T_{1}\left(Q_{2}(y) t\right)+e_{12} T_{2}\left(Q_{2}(y) t\right)+e_{13} T_{3}\left(Q_{2}(y) t\right)\right] \\
& =\frac{1}{\Delta}\left(e_{11} d_{12}+e_{12} d_{22}+e_{13} d_{32}\right) Q_{2} y \\
& =0 \\
Q_{1}\left(Q_{3}(y) t^{2}\right) & =\frac{1}{\Delta}\left[e_{11} T_{1}\left(Q_{3}(y) t^{2}\right)+e_{12} T_{2}\left(Q_{3}(y) t^{2}\right)+e_{13} T_{3}\left(Q_{3}(y) t^{2}\right)\right] \\
& =\frac{1}{\Delta}\left(e_{11} d_{13}+e_{12} d_{23}+e_{13} d_{33}\right) Q_{3} y \\
& =0
\end{aligned}
$$

Similarly, we obtain

$$
Q_{2}\left(Q_{1}(y)\right)=0, \quad Q_{2}\left(Q_{2}(y) t\right)=Q_{2} y, \quad Q_{2}\left(Q_{3}(y) t^{2}\right)=0
$$




$$
Q_{3}\left(Q_{1}(y)\right)=0, \quad Q_{3}\left(Q_{2}(y) t\right)=0, \quad Q_{3}\left(Q_{3}(y) t^{2}\right)=Q_{3} y
$$

Therefore, we get

$$
\begin{aligned}
Q^{2} g= & Q_{1}\left(Q_{1}(y)\right)+Q_{1}\left(Q_{2}(y) t\right)+Q_{1}\left(Q_{3}(y) t^{2}\right)+Q_{2}\left(Q_{1}(y)\right) t+Q_{2}\left(Q_{2}(y) t\right) t \\
& +Q_{2}\left(Q_{3}(y) t^{2}\right) t+Q_{3}\left(Q_{1}(y)\right) t^{2}+Q_{3}\left(Q_{2}(y) t\right) t^{2}+Q_{3}\left(Q_{3}(y) t^{2}\right) t^{2} \\
= & Q_{1}(y)+Q_{2}(y) t+Q_{3}(y) t^{2} \\
= & Q g .
\end{aligned}
$$

This implies that the operator $Q$ is a projector.

Take $y \in Y$ in the form $y=(y-Q y)+Q y$. Then $(y-Q y) \in \operatorname{ker} Q=\operatorname{Im} L$ and $Q y \in \operatorname{Im} Q$. Thus, $Y=\operatorname{Im} Q+\operatorname{Im} L$. And for any $y \in \operatorname{Im} Q \cap \operatorname{Im} L$ from $y \in \operatorname{Im} Q$, there exist constants $\delta_{1}, \delta_{2}, \delta_{3} \in \mathbb{R}$ such that $y(t)=\sum_{k=1}^{3} \delta_{k} t^{k}$, from $y \in \operatorname{Im} L$, we obtain

$$
\left\{\begin{array}{l}
d_{11} \delta_{1}+d_{12} \delta_{2}+d_{13} \delta_{3}=0 \\
d_{21} \delta_{1}+d_{22} \delta_{2}+d_{23} \delta_{3}=0 \\
d_{31} \delta_{1}+d_{32} \delta_{2}+d_{33} \delta_{3}=0
\end{array}\right.
$$

The determinant of coefficients for (3.9) is $\Delta \neq 0$. Therefore, (3.9) has an unique solution $\delta_{1}=\delta_{2}=\delta_{3}=0$, which implies $\operatorname{Im} Q \cap \operatorname{Im} L=0$. Then, we have

$$
Y=\operatorname{Im} Q \oplus \operatorname{ker} Q=\operatorname{Im} Q \oplus \operatorname{Im} L .
$$

Thus, $\operatorname{dim} \operatorname{ker} L=3=\operatorname{dim} \operatorname{Im} Q=\operatorname{codim} \operatorname{ker} Q=\operatorname{codim} \operatorname{Im} L$, this means that $L$ is a Fredholm operator of index zero.

Let $P: X \rightarrow X$ be a mapping defined by

$$
P u(t)=\sum_{k=1}^{3} \frac{u^{(k)}(0)}{k !} t^{k} .
$$

We note that $P$ is a linear continuous projector and $\operatorname{Im} P=\operatorname{ker} L$. It follows from $u=(u-P u)+P u$ that $X=\operatorname{ker} P+\operatorname{ker} L$. By simple calculation, we obtain that ker $L \cap \operatorname{ker} P=\{0\}$. Hence,

$$
X=\operatorname{ker} L \oplus \operatorname{ker} P .
$$

Define $K_{p}: \operatorname{Im} L \rightarrow \operatorname{dom} L \cap \operatorname{ker} P$ as follows:

$$
\left(K_{p} y\right)(t)=\frac{1}{\Gamma(\alpha)} \int_{0}^{t} \frac{(t-s)^{\alpha-1}}{\phi(s)} \int_{0}^{s} y(r) d r d s .
$$

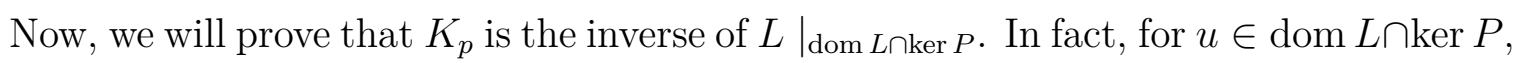
we have

$$
\left(K_{p} L\right) u(t)=I_{0^{+}}^{\alpha}\left(\frac{I_{0^{+}}^{1}\left(\phi^{C} D_{0^{+}}^{\alpha} u\right)^{\prime}}{\phi}\right)(t)=I_{0^{+}}^{\alpha}{ }^{C} D_{0^{+}}^{\alpha} u(t)=u(t)+\sum_{k=0}^{3} \frac{u^{(k)}(0)}{k !} t^{k} .
$$


In view of $u \in \operatorname{dom} L \cap \operatorname{ker} P, u(0)=0$ and $P u=0$. Thus,

$$
\left(K_{p} L\right) u(t)=u(t),
$$

and for $y \in \operatorname{Im} L$, we find

$$
\left(L K_{p}\right) y(t)=L\left(K_{p} y\right)(t)=\left[\phi(t){ }^{C} D_{0^{+}}^{\alpha}\left(I_{0^{+}}^{\alpha}\left(\frac{I_{0^{+}}^{1} y}{\phi}\right)(t)\right)\right]^{\prime}=y(t) .
$$

Thus, $K_{p}=\left(\left.L\right|_{\operatorname{dom} L \cap \operatorname{ker} P}\right)^{-1}$. Again for each $y \in \operatorname{Im} L$, and from Lemmas 2.2, 2.5 and 2.6, we have

$$
\begin{aligned}
\left\|K_{p} y\right\|_{X} & =\sum_{i=0}^{3} \max _{t \in[0,1]}\left|\left(K_{p} y\right)^{(i)}(t)\right|+\max _{t \in[0,1]}\left|{ }^{C} D_{0^{+}}^{\alpha}\left(K_{p} y\right)(t)\right| \\
& =\sum_{i=0}^{3} \max _{t \in[0,1]}\left|I_{0^{+}}^{\alpha-i}\left(\frac{I_{0^{+}}^{1} y}{\phi}\right)(t)\right|+\max _{t \in[0,1]}\left|{ }^{C} D_{0^{+}}^{\alpha} I_{0^{+}}^{\alpha}\left(\frac{I_{0^{+}}^{1} y}{\phi}\right)(t)\right| \\
& \leq \sum_{i=0}^{3}\|y\|_{L^{1}} \max _{t \in[0,1]}\left|I_{0^{+}}^{\alpha-i} \frac{1}{\phi}(t)\right|+\|y\|_{L^{1}} \max _{t \in[0,1]}\left|I_{0^{+}}^{1} \frac{1}{\phi}(t)\right| \\
& \leq \sum_{i=0}^{3}\|y\|_{L^{1}} \max _{t \in[0,1]}\left|I_{0^{+}}^{\alpha-i} \frac{1}{\mu}(t)\right|+\|y\|_{L^{1}} \max _{t \in[0,1]}\left|I_{0^{+}}^{1} \frac{1}{\mu}(t)\right| \\
& \leq \sum_{i=0}^{3} \frac{\|y\|_{L^{1}}}{\mu \Gamma(\alpha+1-i)}+\frac{\|y\|_{L^{1}}}{\mu} \\
& \leq \frac{4+\Gamma(\alpha-2)}{\mu \Gamma(\alpha-2)}\|y\|_{L^{1}} .
\end{aligned}
$$

Lemma 3.3. Suppose that $\Omega$ is an open bounded subset of $X$ such that $\operatorname{dom} L \cap \bar{\Omega} \neq \emptyset$. Then, $N$ is L-compact on $\bar{\Omega}$.

Proof. It is clear that $Q N(\bar{\Omega})$ and $K_{p}(I-Q) N(\bar{\Omega})$ are bounded, due to the fact that $f$ realize the caratheodory conditions.

Using the Lebesgue dominated convergence theorem, we can easily find that $Q N$ and $K_{P, Q} N=K_{p}(I-Q) N: \bar{\Omega} \rightarrow X$ are continuous. By the hypothesis (iii) on the function $f$, there exists a constant $A>0$, such that $|(I-Q) N(u(t))| \leq A$, for all $u \in \Omega$, $t \in[0,1]$. For $i=0,1,2,3,0 \leq t_{1} \leq t_{2} \leq 1$, and $u \in \Omega$, we put $M(t)=(I-Q) N u(t)$. One has

$$
\begin{aligned}
& \left|\left(K_{P, Q} N u\right)^{(i)}\left(t_{2}\right)-\left(K_{P, Q} N u\right)^{(i)}\left(t_{1}\right)\right| \\
= & \frac{1}{\Gamma(\alpha-i)}\left|\int_{0}^{t_{2}} \frac{\left(t_{2}-s\right)^{\alpha-i-1}}{\phi(s)} \int_{0}^{s} M(r) d r d s-\int_{0}^{t_{1}} \frac{\left(t_{1}-s\right)^{\alpha-i-1}}{\phi(s)} \int_{0}^{s} M(r) d r d s\right| \\
\leq & \frac{A}{\mu \Gamma(\alpha-i)}\left\{\int_{0}^{t_{1}}\left(t_{2}-s\right)^{\alpha-i-1}-\left(t_{1}-s\right)^{\alpha-i-1} d s+\int_{t_{1}}^{t_{2}}\left(t_{2}-s\right)^{\alpha-i-1} d s\right\} \\
= & \frac{A}{\mu \Gamma(\alpha+1-i)}\left(t_{2}^{\alpha-i}-t_{1}^{\alpha-i}\right),
\end{aligned}
$$


Furthermore, we have

$$
\begin{aligned}
& \left|{ }^{C} D_{0^{+}}^{\alpha} K_{P, Q} N u\left(t_{2}\right)-{ }^{C} D_{0^{+}}^{\alpha} K_{P, Q} N u\left(t_{1}\right)\right| \\
= & \left|\frac{1}{\phi\left(t_{2}\right)} \int_{0}^{t_{2}} M(s) d s-\frac{1}{\phi\left(t_{1}\right)} \int_{0}^{t_{1}} M(s) d s\right| \\
= & \left|\left(\frac{1}{\phi\left(t_{2}\right)}-\frac{1}{\phi\left(t_{1}\right)}\right) \int_{0}^{t_{1}} M(s) d s+\frac{1}{\phi\left(t_{2}\right)} \int_{t_{1}}^{t_{2}} M(s) d s\right| \\
\leq & \frac{A}{\mu^{2}}\left|\phi\left(t_{2}\right)-\phi\left(t_{1}\right)\right|+\frac{A}{\mu}\left(t_{2}-t_{1}\right) .
\end{aligned}
$$

Since $t^{\alpha-i}$ and $\phi(t)$ are uniformly continuous on $[0,1]$, we get that $K_{p}(I-Q) N: \bar{\Omega} \rightarrow X$ is compact. The lemma is proved.

Theorem 3.1. Let $f$ be a Caratheodory function, $\phi \in C^{1}[0,1], \min _{t \in[0,1]} \phi(t)>\mu>0$. $\left(H_{1}\right)$ and $\left(H_{2}\right)$ hold. In addition, assume that the following conditions hold.

$\left(H_{3}\right)$ There exist non-negative functions $\theta_{i}(t) \in Y, i=0, \ldots, 5$, such that

$$
\left|f\left(t, x_{0}, x_{1}, x_{2}, x_{3}, x_{4}\right)\right| \leq \sum_{i=0}^{4} \theta_{i}(t)\left|x_{i}\right|+\theta_{5}(t),
$$

where

$$
\Lambda=\frac{22+\Gamma(\alpha-2)}{\mu \Gamma(\alpha-2)} \sum_{i=0}^{4}\left\|\theta_{i}\right\|_{L^{1}}<1 .
$$

$\left(H_{4}\right)$ There exists a constant $M>0$ such that for $u \in \operatorname{dom} L \backslash \operatorname{ker} L$, if $\left|u^{\prime}(t)\right|>M$ or $\left|u^{\prime \prime}(t)\right|>M$ or $\left|u^{\prime \prime \prime}(t)\right|>M$ for all $t \in[0,1]$, then $T_{1}(N u) \neq 0$ or $T_{2}(N u) \neq 0$ or $T_{3}(N u) \neq 0$.

$\left(H_{5}\right)$ There exists a constant $M^{*}>0$ such that for any $\delta_{1}, \delta_{2}, \delta_{3} \in \mathbb{R}$, if $\left|\delta_{1}\right|>M^{*}$, $\left|\delta_{2}\right|>M^{*},\left|\delta_{3}\right|>M^{*}$, then either

$$
\sum_{i=1}^{3} T_{i} N\left(\sum_{k=1}^{3} \delta_{k} t^{k}\right)<0
$$

or

$$
\sum_{i=1}^{3} T_{i} N\left(\sum_{k=1}^{3} \delta_{k} t^{k}\right)>0
$$

Then (1.1) has at least one solution.

Proof. Consider the set

$$
\Omega_{1}=\{u \in \operatorname{dom} L \backslash \operatorname{ker} L: L u=\lambda N u, \lambda \in[0,1]\} .
$$

Then for $u \in \Omega_{1}, L u=\lambda N u$, thus $\lambda \neq 0, N u \in \operatorname{Im} L=\operatorname{ker} Q \subset Y$. Hence, $Q(N u)=0$ that is, $T_{1}(N u)=T_{2}(N u)=T_{3}(N u)=0$. We get from $\left(H_{4}\right)$ the existence of $t_{1}, t_{2}, t_{3} \in[0,1]$, such that $\left|u^{\prime}\left(t_{1}\right)\right| \leq M,\left|u^{\prime \prime}\left(t_{2}\right)\right| \leq M,\left|u^{\prime \prime \prime}\left(t_{3}\right)\right| \leq M$. 
If $t_{1}=t_{2}=t_{3}=0$, we have that $\left|u^{\prime}(0)\right| \leq M,\left|u^{\prime \prime}(0)\right| \leq M,\left|u^{\prime \prime \prime}(0)\right| \leq M$. Otherwise, if $\max \left\{t_{1}, t_{2}, t_{3}\right\} \neq 0$, by $L u=\lambda N u$, we obtain

$$
u(t)=\sum_{k=1}^{3} \frac{u^{(k)}(0)}{k !} t^{k}+\frac{\lambda}{\Gamma(\alpha)} \int_{0}^{t} \frac{(t-s)^{\alpha-1}}{\phi(s)} \int_{0}^{s} N u(r) d r d s .
$$

Then

$$
u^{\prime \prime \prime}(t)=u^{\prime \prime \prime}(0)+\frac{\lambda}{\Gamma(\alpha-3)} \int_{0}^{t} \frac{(t-s)^{\alpha-4}}{\phi(s)} \int_{0}^{s} N u(r) d r d s .
$$

If $t_{3} \neq 0$, we get

$$
u^{\prime \prime \prime}\left(t_{3}\right)=u^{\prime \prime \prime}(0)+\frac{\lambda}{\Gamma(\alpha-3)} \int_{0}^{t_{3}} \frac{\left(t_{3}-s\right)^{\alpha-4}}{\phi(s)} \int_{0}^{s} N u(r) d r d s
$$

together with $\left|u^{\prime \prime \prime}\left(t_{3}\right)\right| \leq M$, we have

$$
\left|u^{\prime \prime \prime}(0)\right| \leq\left|u^{\prime \prime \prime}\left(t_{3}\right)\right|+\frac{1}{\Gamma(\alpha-3)} \int_{0}^{t_{3}} \frac{\left(t_{3}-s\right)^{\alpha-4}}{\phi(s)} \int_{0}^{s}|N u(r)| d r d s \leq M+\frac{\|N u\|_{L^{1}}}{\mu \Gamma(\alpha-2)} .
$$

Therefore,

$$
\left|u^{\prime \prime \prime}(0)\right| \leq M+\frac{\|N u\|_{L^{1}}}{\mu \Gamma(\alpha-2)}
$$

If $t_{2} \neq 0$, then

$$
u^{\prime \prime}\left(t_{2}\right)=u^{\prime \prime}(0)+u^{\prime \prime \prime}(0) t_{2}+\frac{\lambda}{\Gamma(\alpha-2)} \int_{0}^{t_{2}} \frac{\left(t_{2}-s\right)^{\alpha-3}}{\phi(s)} \int_{0}^{s} N u(r) d r d s,
$$

from (3.14) and $\left|u^{\prime \prime}\left(t_{2}\right)\right| \leq M$, we find

$$
\begin{aligned}
\left|u^{\prime \prime}(0)\right| & \leq\left|u^{\prime \prime}\left(t_{2}\right)\right|+\left|u^{\prime \prime \prime}(0)\right|+\frac{1}{\Gamma(\alpha-2)} \int_{0}^{t_{2}} \frac{\left(t_{2}-s\right)^{\alpha-3}}{\phi(s)} \int_{0}^{s}|N u(r)| d r d s \\
& \leq 2 M+\frac{2\|N u\|_{L^{1}}}{\mu \Gamma(\alpha-2)} .
\end{aligned}
$$

Consequently,

$$
\left|u^{\prime \prime}(0)\right| \leq 2 M+\frac{2\|N u\|_{L^{1}}}{\mu \Gamma(\alpha-2)}
$$

If $t_{1} \neq 0$, then

$$
u^{\prime}\left(t_{1}\right)=u^{\prime}(0)+u^{\prime \prime}(0) t_{1}+\frac{u^{\prime \prime \prime}(0)}{2} t_{1}^{2}+\frac{\lambda}{\Gamma(\alpha-1)} \int_{0}^{t_{1}} \frac{\left(t_{1}-s\right)^{\alpha-2}}{\phi(s)} \int_{0}^{s} N u(r) d r d s,
$$

according to (3.14), (3.15) and $\left|u^{\prime}\left(t_{1}\right)\right| \leq M$, we get

$$
\begin{aligned}
\left|u^{\prime}(0)\right| & \leq\left|u^{\prime}\left(t_{1}\right)\right|+\left|u^{\prime \prime}(0)\right|+\left|u^{\prime \prime \prime}(0)\right|+\frac{1}{\Gamma(\alpha-1)} \int_{0}^{t_{1}} \frac{\left(t_{1}-s\right)^{\alpha-2}}{\phi(s)} \int_{0}^{s}|N u(r)| d r d s \\
& \leq 4 M+\frac{4\|N u\|_{L^{1}}}{\mu \Gamma(\alpha-2)}
\end{aligned}
$$


So,

$$
\left|u^{\prime}(0)\right| \leq 4 M+\frac{4\|N u\|_{L^{1}}}{\mu \Gamma(\alpha-2)}
$$

Again for $u \in \Omega_{1}$, we get

$$
\begin{aligned}
\|P u\|_{X} & =\sum_{i=0}^{3} \max _{t \in[0,1]}\left|(P u)^{(i)}(t)\right|+\max _{t \in[0,1]}\left|{ }^{C} D_{0^{+}}^{\alpha}(P u)(t)\right| \\
& \leq 2\left|u^{\prime}(0)\right|+3\left|u^{\prime \prime}(0)\right|+4\left|u^{\prime \prime \prime}(0)\right| .
\end{aligned}
$$

From (3.14), (3.15) and (3.16), we obtain

$$
\|P u\|_{X} \leq 18 M+\frac{18\|N u\|_{L^{1}}}{\mu \Gamma(\alpha-2)}
$$

Again for all $u \in \Omega_{1}$, we have $(I-P) u \in \operatorname{dom} L \cap$ ker $P$. Thus, by (3.13) and (3.5), we find

$$
\begin{aligned}
\|(I-P) u\|_{X} & =\left\|K_{p} L(I-P) u\right\|_{X} \leq \frac{4+\Gamma(\alpha-2)}{\mu \Gamma(\alpha-2)}\|L(I-P) u\|_{L^{1}} \\
& \leq \frac{4+\Gamma(\alpha-2)}{\mu \Gamma(\alpha-2)}\|L u\|_{L^{1}} \\
& \leq \frac{4+\Gamma(\alpha-2)}{\mu \Gamma(\alpha-2)}\|N u\|_{L^{1}} .
\end{aligned}
$$

From (3.17) and (3.18), we obtain

$$
\|u\|_{X} \leq\|P u\|_{X}+\|(I-P) u\|_{X} \leq 18 M+\frac{22+\Gamma(\alpha-2)}{\mu \Gamma(\alpha-2)}\|N u\|_{L^{1}} .
$$

On the other hand, from $\left(H_{4}\right)$, we have

$$
\begin{aligned}
\|N u\|_{L^{1}} & =\int_{0}^{1}|(N u)(s)| d s=\int_{0}^{1}\left|f\left(t, u(t), u^{\prime}(t), u^{\prime \prime}(t), u^{\prime \prime \prime}(t),{ }^{C} D_{0^{+}}^{\alpha} u(t)\right)\right| d s \\
& \leq \sum_{i=0}^{3} \int_{0}^{1}\left|\theta_{i}(s)\left\|u^{(i)}(s)\left|d s+\int_{0}^{1}\right| \theta_{4}(s)\right\|{ }^{C} D_{0^{+}}^{\alpha} u(s)\right| d s+\int_{0}^{1}\left|\theta_{5}(s)\right| d s \\
& \leq\|u\|_{X} \sum_{i=0}^{4}\left\|\theta_{i}\right\|_{L^{1}}+\left\|\theta_{5}\right\|_{L^{1}} .
\end{aligned}
$$

Therefore, (3.19) and (3.20), yields

$$
\|u\|_{X} \leq \frac{18 \mu \Gamma(\alpha-2) M+(22+\Gamma(\alpha-2))\left\|\theta_{5}\right\|_{L^{1}}}{\mu(1-\Lambda) \Gamma(\alpha-2)} .
$$

So, $\Omega_{1}$ is bounded.

Let

$$
\Omega_{2}=\{u \in \operatorname{ker} L: N u \in \operatorname{Im} L\} .
$$


For $u \in \Omega_{2}$, then $u \in \operatorname{ker} L=\left\{u: u(t)=\sum_{k=1}^{3} \delta_{k} t^{k}, \delta_{1}, \delta_{2}, \delta_{3} \in \mathbb{R}\right\}$ and $Q(N u)=0$, that is, $T_{1} N\left(\sum_{k=1}^{3} \delta_{k} t^{k}\right)=T_{2} N\left(\sum_{k=1}^{3} \delta_{k} t^{k}\right)=T_{3} N\left(\sum_{k=1}^{3} \delta_{k} t^{k}\right)=0$. From condition $\left(H_{5}\right)$, we get $\left|\delta_{1}\right| \leq M^{*},\left|\delta_{2}\right| \leq M^{*},\left|\delta_{3}\right| \leq M^{*}$. Hence, $\Omega_{2}$ is bounded. Let

$$
\Omega_{3}=\{u \in \operatorname{ker} L:-\lambda J u+(1-\lambda) Q N u=0, \lambda \in[0,1]\},
$$

if the first part of $\left(H_{5}\right)$ holds.

Or we'll set

$$
\Omega_{3}=\{u \in \operatorname{ker} L:-\lambda J u+(1-\lambda) Q N u=0, \lambda \in[0,1]\}
$$

if the second part of $\left(H_{5}\right)$ holds.

Here $J: \operatorname{ker} L \rightarrow \operatorname{Im} Q$ is the linear isomorphism given by

$$
J\left(\sum_{k=1}^{3} \delta_{k} t^{k}\right)=\omega_{1}+\omega_{2} t+\omega_{3} t^{2}, \quad \delta_{1}, \delta_{2}, \delta_{3} \in \mathbb{R},
$$

where

$$
\begin{aligned}
& \omega_{1}=\frac{1}{\Delta}\left(e_{11}\left|\delta_{1}\right|+e_{12}\left|\delta_{2}\right|+e_{13}\left|\delta_{3}\right|\right), \\
& \omega_{2}=\frac{1}{\Delta}\left(e_{21}\left|\delta_{1}\right|+e_{22}\left|\delta_{2}\right|+e_{23}\left|\delta_{3}\right|\right), \\
& \omega_{3}=\frac{1}{\Delta}\left(e_{31}\left|\delta_{1}\right|+e_{32}\left|\delta_{2}\right|+e_{33}\left|\delta_{3}\right|\right) .
\end{aligned}
$$

Without loss of generality, we assume that the first part of $\left(H_{5}\right)$ holds. In fact $u \in \Omega_{3}$, means that $u=\sum_{k=1}^{3} \delta_{k} t^{k}$ and $-\lambda J u+(1-\lambda) Q N u=0$. Then we obtain

$$
-\lambda J\left(\sum_{k=1}^{3} \delta_{k} t^{k}\right)+(1-\lambda) Q N\left(\sum_{k=1}^{3} \delta_{k} t^{k}\right)=0 .
$$

If $\lambda=0$, then $\left|\delta_{1}\right| \leq M^{*},\left|\delta_{2}\right| \leq M^{*},\left|\delta_{3}\right| \leq M^{*}$. If $\lambda=1$, then

$$
\left\{\begin{array}{l}
e_{11}\left|\delta_{1}\right|+e_{12}\left|\delta_{2}\right|+e_{13}\left|\delta_{3}\right|=0, \\
e_{21}\left|\delta_{1}\right|+e_{22}\left|\delta_{2}\right|+e_{23}\left|\delta_{3}\right|=0, \\
e_{31}\left|\delta_{1}\right|+e_{32}\left|\delta_{2}\right|+e_{33}\left|\delta_{3}\right|=0 .
\end{array}\right.
$$

The determinant of coefficients for (3.23) is $\Delta^{2} \neq 0$. Thus, (3.23) only have zero solutions, that is $\delta_{1}=\delta_{2}=\delta_{3}=0$.

Otherwise, if $\lambda \neq 0$ and $\lambda \neq 1$, again from (3.21), (3.22) becomes

$$
\begin{aligned}
\lambda\left(\omega_{1}+\omega_{2} t+\omega_{3} t^{2}\right)= & (1-\lambda)\left(Q_{1} N\left(\sum_{k=1}^{3} \delta_{k} t^{k}\right)+Q_{2} N\left(\sum_{k=1}^{3} \delta_{k} t^{k}\right) t\right. \\
& \left.+Q_{3} N\left(\sum_{k=1}^{3} \delta_{k} t^{k}\right) t^{2}\right)
\end{aligned}
$$

Hence,

$$
\lambda \omega_{i}=(1-\lambda) Q_{i}\left(\sum_{k=1}^{3} \delta_{k} t^{k}\right), \quad \text { for } i=1,2,3 .
$$


Thus,

Then, we get

$$
\lambda\left|\delta_{i}\right|=(1-\lambda) T_{i} N\left(\sum_{k=1}^{3} \delta_{k} t^{k}\right), \quad \text { for } i=1,2,3 .
$$

$$
\lambda \sum_{i=1}^{3}\left|\delta_{i}\right|=(1-\lambda) \sum_{i=1}^{3} T_{i} N\left(\sum_{k=1}^{3} \delta_{k} t^{k}\right)<0 .
$$

By the first part of $\left(H_{5}\right)$, we have $\left|\delta_{1}\right| \leq M^{*},\left|\delta_{2}\right| \leq M^{*},\left|\delta_{3}\right| \leq M^{*}$. Here, $\Omega_{3}$ is bounded.

Now, we shall prove that all the conditions of Theorem 2.1 are satisfied. Let $\Omega$ be a bounded open set of $X$ containing $\bigcup_{i=1}^{3} \bar{\Omega}_{i}$. By Lemma 3.3, $\mathrm{N}$ is L-compact on $\bar{\Omega}$, because $\Omega_{1}$ and $\Omega_{2}$ are bounded sets, then

(1) $L u \neq \lambda N u$ for each $(u, \lambda) \in[(\operatorname{dom} L \backslash \operatorname{ker} L) \cap \partial \Omega] \times(0,1)$;

(2) $N u \notin \operatorname{Im} L$ for each $u \in \operatorname{ker} L \cap \partial \Omega$.

At least we will prove that the hypothesis (3) of Theorem 2.1 is satisfied. Let

$$
H(u, \lambda)= \pm \lambda J u+(1-\lambda) Q N u \text {. }
$$

The set $\Omega_{3}$ is bounded, then $H(u, \lambda) \neq 0$, for all $u \in \operatorname{ker} L \cap \partial \Omega$. Appealing to the homotopy property of the degree, we obtain

$$
\begin{aligned}
\operatorname{deg}\left(\left.Q N\right|_{\operatorname{ker} L}, \Omega \cap \operatorname{ker} L, 0\right) & =\operatorname{deg}(H(., 0), \Omega \cap \operatorname{ker} L, 0) \\
& =\operatorname{deg}(H(., 1), \Omega \cap \operatorname{ker} L, 0) \\
& =\operatorname{deg}( \pm J, \Omega \cap \operatorname{ker} L, 0) \neq 0 .
\end{aligned}
$$

Then by Theorem $2.1, L u=N u$ has at least one solution in dom $L \cap \bar{\Omega}$, we conclude that the boundary value problem (1.1) has at least one solution in $X$. The proof is finished.

Remark 3.1. It is very important to note that the condition $\Delta \neq 0$ is not necessary since $L$ still Fredholm even if this condition is dropped. Indeed the role of $Q$ in Mawhin's theory is purely auxiliary and conditions like that usually arise from the authors of hundreds of paper choosing $\operatorname{Im} Q$ just simply being ker $L$. Avoiding such an assumption is just a matter of choosing $Q$ differently, for more details see $[14,20,21]$.

\section{EXAMPLE}

To illustrate our main results, we will present an example.

Example 4.1. Let us consider the following fractional boundary value problem

$$
\left\{\begin{array}{l}
\left(\phi(t){ }^{C} D_{0^{+}}^{\frac{7}{2}} u(t)\right)^{\prime}=f\left(t, u(t), u^{\prime}(t), u^{\prime \prime}(t), u^{\prime \prime \prime}(t),{ }^{C} D_{0^{+}}^{\frac{7}{2}} u(t)\right), \quad t \in[0,1], \\
u(0)=0, \quad{ }^{C} D_{0^{+}}^{\alpha} u(0)=0, \quad u^{\prime \prime \prime}(0)=-u^{\prime \prime \prime}\left(\frac{1}{6}\right)+2 u^{\prime \prime \prime}\left(\frac{1}{5}\right) \\
u^{\prime \prime}(0)=4 u^{\prime \prime}\left(\frac{1}{4}\right)-3 u^{\prime \prime}\left(\frac{1}{3}\right), \quad u^{\prime}(1)=u^{\prime}\left(\frac{1}{4}\right)-3 u^{\prime}\left(\frac{1}{2}\right)+3 u^{\prime}\left(\frac{3}{4}\right)
\end{array}\right.
$$


where $\phi(t)=e^{-12 t}$ and

$$
\begin{aligned}
& 100 e^{12} f\left(t, u(t), u^{\prime}(t), u^{\prime \prime}(t), u^{\prime \prime \prime}(t),{ }^{C} D_{0^{+}}^{\frac{7}{2}} u(t)\right) \\
= & \frac{\left|u^{\prime \prime \prime}(t)\right|}{1+\left(u^{\prime \prime \prime}(t)\right)^{2}}+\cos { }^{C} D_{0^{+}}^{\frac{7}{2}} u(t)\left(1-\sin u^{\prime}(t)\right)\left(1-\sin u^{\prime \prime}(t)\right) \\
& +\frac{2}{\pi} \arctan \left(u(t)^{C} D_{0^{+}}^{\frac{7}{2}} u(t)\right) .
\end{aligned}
$$

Corresponding to the problem (1.1), we have that $\alpha=\frac{7}{2}, l=2, m=2, n=3, a_{1}=$ $-1, a_{2}=2, \xi_{1}=\frac{1}{6}, \xi_{2}=\frac{1}{5}, b_{1}=4, b_{2}=-3, \eta_{1}=\frac{1}{4}, \eta_{2}=\frac{1}{3}, c_{1}=1, c_{2}=-3, c_{3}=$ $3, \rho_{1}=\frac{1}{4}, \rho_{2}=\frac{1}{2}, \rho_{3}=\frac{3}{4}, \mu=e^{-12}$. Then we get $a_{1}+a_{2}=b_{1}+b_{2}=c_{1}+c_{2}+c_{3}=$ $1, b_{1} \eta_{1}+b_{2} \eta_{2}=0, c_{1} \rho_{1}+c_{2} \rho_{2}+c_{3} \rho_{3}=c_{1} \rho_{1}^{2}+c_{2} \rho_{2}^{2}+c_{3} \rho_{3}^{2}=1$. Thus, the condition $\left(H_{1}\right)$ holds.

Also, we find

$$
\begin{aligned}
T_{1}(y)= & -\int_{0}^{\frac{1}{6}} e^{12 s}\left(\frac{1}{6}-s\right)^{-\frac{1}{2}} \int_{0}^{s} y(r) d r d s+2 \int_{0}^{\frac{1}{5}} e^{12 s}\left(\frac{1}{5}-s\right)^{-\frac{1}{2}} \int_{0}^{s} y(r) d r d s, \\
T_{2}(y)= & 4 \int_{0}^{\frac{1}{4}} e^{12 s}\left(\frac{1}{4}-s\right)^{\frac{1}{2}} \int_{0}^{s} y(r) d r d s-3 \int_{0}^{\frac{1}{3}} e^{12 s}\left(\frac{1}{3}-s\right)^{\frac{1}{2}} \int_{0}^{s} y(r) d r d s, \\
T_{3}(y)= & \int_{0}^{1} e^{12 s}(1-s)^{\frac{3}{2}} \int_{0}^{s} y(r) d r d s-\int_{0}^{\frac{1}{4}} e^{12 s}\left(\frac{1}{4}-s\right)^{\frac{3}{2}} \int_{0}^{s} y(r) d r d s \\
& +3 \int_{0}^{\frac{1}{2}} e^{12 s}\left(\frac{1}{2}-s\right)^{\frac{3}{2}} \int_{0}^{s} y(r) d r d s-3 \int_{0}^{\frac{3}{4}} e^{12 s}\left(\frac{3}{4}-s\right)^{\frac{3}{2}} \int_{0}^{s} y(r) d r d s .
\end{aligned}
$$

By calculations, we get

$$
\begin{aligned}
& d_{11}=\frac{1881}{1420}, \quad d_{12}=\frac{207}{1669}, \quad d_{13}=\frac{143}{9103} \\
& d_{21}=-\frac{920}{1803}, \quad d_{22}=-\frac{484}{6725}, \quad d_{23}=-\frac{277}{20262}, \\
& d_{31}=\frac{15770}{51}, \quad d_{32}=\frac{6489}{50}, \quad d_{33}=\frac{5427}{74} .
\end{aligned}
$$

Then, $\Delta=-\frac{655}{539} \neq 0$. Therefore, the condition $\left(H_{2}\right)$ holds.

On the other hand, we have

$$
\left|f\left(t, u(t), u^{\prime}(t), u^{\prime \prime}(t), u^{\prime \prime \prime}(t),{ }^{C} D_{0^{+}}^{\frac{7}{2}} u(t)\right)\right| \leq 0.01 e^{-12}\left|u^{\prime \prime \prime}(t)\right|+0.05 e^{-12} .
$$

We can get that the condition $\left(H_{3}\right)$ holds, where

$$
\theta_{0}(t)=\theta_{1}(t)=\theta_{2}(t)=\theta_{4}(t)=0, \quad \theta_{3}(t)=0.01 e^{-12}, \quad \theta_{5}(t)=0.05 e^{-12}
$$

and $\Lambda=\frac{838}{3245}<1$.

Let $M=1$ and assume that $\left|u^{\prime \prime \prime}(t)\right|>1$ holds for all $t \in[0,1]$, we obtain

$$
T_{3}(y)>0.01 e^{-12} \int_{0}^{1} e^{12 s}(1-s)^{\frac{3}{2}} s d s-0.06 e^{-12} \int_{0}^{\frac{1}{4}} e^{12 s}\left(\frac{1}{4}-s\right)^{\frac{3}{2}} s d s
$$




$$
\begin{aligned}
& +0.03 e^{-12} \int_{0}^{\frac{1}{2}} e^{12 s}\left(\frac{1}{2}-s\right)^{\frac{3}{2}} s d s-0.18 e^{-12} \int_{0}^{\frac{3}{4}} e^{12 s}\left(\frac{3}{4}-s\right)^{\frac{3}{2}} s d s . \\
= & \frac{43818}{2900} e^{-12}>0,
\end{aligned}
$$

so condition $\left(H_{4}\right)$ is satisfied.

Let $M^{*}=1$ and $\delta_{1}, \delta_{2}, \delta_{3} \in \mathbb{R}$ be such that $\left|\delta_{1}\right|>1,\left|\delta_{2}\right|>1,\left|\delta_{3}\right|>1$, we have

$$
\begin{aligned}
N\left(\delta_{1} t+\delta_{2} t^{2}+\delta_{3} t^{3}\right)= & 0.06 e^{-12} \frac{\left|\delta_{3}\right|}{1+36 \delta_{3}^{2}}+0.01 e^{-12} \cos ^{C} D_{0^{+}}^{\frac{7}{2}}\left(\delta_{1} t+\delta_{2} t^{2}+\delta_{3} t^{3}\right) \\
& \times\left(1-\sin \left(\delta_{1}+2 \delta_{2} t+3 \delta_{3} t^{2}\right)\right) \times\left(1-\sin \left(2 \delta_{2}+6 \delta_{3} t\right)\right) \\
& +\frac{0.02 e^{-12}}{\pi} \arctan \left(\left(\delta_{1} t+\delta_{2} t^{2}+\delta_{3} t^{3}\right)^{C} D_{0^{+}}^{\frac{7}{2}}\left(\delta_{1} t+\delta_{2} t^{2}+\delta_{3} t^{3}\right)\right) \\
= & 0.06 e^{-12} \frac{\left|\delta_{3}\right|}{1+36 \delta_{3}^{2}} .
\end{aligned}
$$

Hence,

$$
\begin{aligned}
& T_{1} N\left(\sum_{k=1}^{3} \delta_{k} t^{k}\right)=0.06 e^{-12} \frac{\left|\delta_{3}\right|}{1+36 \delta_{3}^{2}} d_{11}, \\
& T_{2} N\left(\sum_{k=1}^{3} \delta_{k} t^{k}\right)=0.06 e^{-12} \frac{\left|\delta_{3}\right|}{1+36 \delta_{3}^{2}} d_{12}, \\
& T_{3} N\left(\sum_{k=1}^{3} \delta_{k} t^{k}\right)=0.06 e^{-12} \frac{\left|\delta_{3}\right|}{1+36 \delta_{3}^{2}} d_{13} .
\end{aligned}
$$

Thus,

$$
\sum_{i=1}^{3} T_{i} N\left(\sum_{k=1}^{3} \delta_{k} t^{k}\right)=0.06 e^{-12} \frac{\left|\delta_{3}\right|}{1+36 \delta_{3}^{2}}\left(d_{11}+d_{12}+d_{13}\right)>0 .
$$

So, $\left(H_{5}\right)$ hold. Then, all the assumptions of Theorem 3.1 hold. Thus, the problem (4.1) has at least one solution.

\section{REFERENCES}

[1] B. Ahmad and P. Eloe, A nonlocal boundary value problem for a nonlinear fractional differential equation with two indices, Comm. Appl. Nonlinear Anal. 17 (2010), 69-80.

[2] R. P. Agarwal, D. O'Regan and S. Stanek, Positive solutions for Dirichlet problems of singular nonlinear fractional differential equations, J. Math. Anal. Appl. 371 (2010), 57-68.

[3] Z. Bai, On solutions of some fractional m-point boundary value problems at resonance, Electron. J. Qual. Theory Differ. Equ. 37 (2010), 15 pages, Paper ID MR2676127.

[4] Z. Bai, Solvability for a class of fractional m-point boundary value problem at resonance, Comput. Math. Appl. 62 (2011), 1292-1302.

[5] Z. Bai and Y. Zhang, The existence of solutions for a fractional multi-point boundary value problem, Comput. Math. Appl. 60(8) (2010), 2364-2372.

[6] Z. Bai and Y. Zhang, Solvability of fractional three-point boundary value problems with nonlinear growth, Appl. Math. Comput. 218 (2011), 1719-1725. 
[7] M. Benchohra, S. Hamani and S. K. Ntouyas, Boundary value problems for differential equations with fractional order and nonlocal conditions, Nonlinear Anal. 71 (2009), 2391-2396.

[8] S. Djebali and L. Guedda, A third order boundary value problem with nonlinear growth at resonance on the half-axis, Math. Meth. Appl. Sci. (2016).

[9] Z. Hu, W. Liu and T. Chen, Existence of solutions for a coupled system of fractional differential equations at resonance, Bound. Value Probl. 2012(98) (2012), 13 pages.

[10] Z. Hu, W. Liu and T. Chen, Two-point boundary value problems for fractional differential equations at resonance, Bull. Malays. Math. Sci. Soc. 36(3) (2013), 747-755.

[11] L. Hu, S. Zhang and A. Shi, Existence of solutions for two-point boundary value problem of fractional differential equations at resonance, Hindawi Publishing Corporation International Journal of Differential Equations (2014), Article ID 632434, 7 pages.

[12] H. Jafari and V. D. Gejji, Positive solutions of nonlinear fractional boundary value problems using Adomian decomposition method, Appl. Math. Comput. 180 (2006) 700-706.

[13] M. Jia and X. Liu, Multiplicity of solutions for integral boundary value problems of fractional differential equations with upper and lower solutions, Appl. Math. Comput. 232 (2014), 313-323.

[14] W. Jiang and N. Kosmatov, Solvability of a third-order differential equation with functional boundary conditions at resonance, Bound. Value Probl. 81 (2017), DOI 10.1186/s13661-017-0811$\mathrm{z}$.

[15] W. Jiang, The existence of solutions to boundary value problems of fractional differential equations at resonance, Nonlinear Anal. TMA 74 (2011), 1987-1994.

[16] W. Jiang, Solvability for a coupled system of fractional differential equations at resonance, Nonlinear Anal. Real World Appl. 13 (2012), 2285-2292.

[17] A. A. Kilbas, H. M. Srivastava and J. J. Trujillo, Theory and Applications of Fractional Differential Equations, North-Holland Mathematics Studies 204, Elsevier Science B.V., Amsterdam, 2006.

[18] N. Kosmatov, Multi-point boundary value problems on an unbounded domain at resonance, Nonlinear Anal. 68 (2010), 2158-2171.

[19] N. Kosmatov, A boundary value problem of fractional order at resonance, Electron. J. Differ. Equ. 135 (2010), 10 pages.

[20] N. Kosmatov and W. Jiang, Second-order functional problems with a resonance of dimension one, Differ. Equ. Appl. 3 (2016), 349-365.

[21] N. Kosmatov and W. Jiang, Resonant functional problems of fractional order, Chaos Solitons Fractals 91 (2016), 573-579.

[22] S. Li, J. Yin and Z. Du, Solutions to third-order multi-point boundary-value problems at resonance with three dimensional kernels, Electron. J. Differ. Equ. (2014), Article ID 61.

[23] S. Liang and J. Zhang, Existence and uniqueness of positive solutions to m-point boundary value problem for nonlinear fractional differential equation, J. Appl. Math. Comput. 38 (2012), 225-241.

[24] X. Lin, B. Zhao and Z. Du, Athird-order multi-point boundary value problem at resonance with one three dimensional kernel space, Carpathian J. Math. 30(1) (2014), 93-100.

[25] J. Mawhin, Topological Degree Methods in Nonlinear Boundary Value Problems, NSF-CBMS Regional Conference Series in Mathematics 40, American Mathematical Society, Providence, RI, 1979 .

[26] K. S. Miller and B. Ross, An Introduction to the Fractional Calculus and Fractional Differential Equations, A Wiley-Interscience Publication, John Wiley Sons, New York, NY, USA, 1993.

[27] K. B. Oldham and J. Spanier, The Fractional Calculus, Academic Press, New York, 1974.

[28] I. Podlubny, Geometric and physical interpretation of fractional integration and fractional differentiation, Fract. Calc. Appl. Anal. 5 (2002), 367-386.

[29] M. Rehman and P. Eloe, Existence and uniqueness of solutions for impulsive fractional differential equations, Appl. Math. Comput. 224 (2013), 422-431. 
[30] S. G. Samko, A. A. Kilbas and O. I. Marichev, Fractional Integrals and Derivatives. Theory and Applications, Gordon and Breach, Yverdon, 1993.

[31] N. Xu, W. Liu, and L. Xiao, The existence of solutions for nonlinear fractional multipoint boundary value problems at resonance, Bound. Value Probl. 2012 (2012), Article ID 65, 10 pages.

[32] Y. Zhang and Z. Bai, Existence of solution for nonlinear fractional three-point boundary value problems at resonances, J. Appl. Math. Comput. 36 (2011), 417-440.

[33] X. Zhang, L. Wang and Q. Sun, Existence of positive solutions for a class of nonlinear fractional differential equations with integral boundary conditions and a parameter, Appl. Math. Comput. 226 (2014), 708-718.

${ }^{1}$ Laboratoire de Mathématiques et Sciences appliquÉEs, UNIVERSITY OF GHARDAIA,

AlgERIA.

Email address: baitichezidane19@gmail.com

Email address: guerbati_k@yahoo.com

${ }^{2}$ Department of Mathematics and Computer Sciences, University of Khemis MiLiana,

Algeria.

Email address: mbenbachir2001@gmail.com 